\title{
New Zealand Medical Students Have Positive Attitudes and Moderate Confidence in Providing Nutrition Care: A Cross-Sectional Survey
}

\author{
Jennifer Crowley, ${ }^{1}$ Lauren Ball, ${ }^{2}$ Dug Yeo Han, ${ }^{1}$ Bruce Arroll, ${ }^{3}$ \\ Michael Leveritt, ${ }^{4}$ and Clare Wall ${ }^{1}$ \\ ${ }^{1}$ Discipline of Nutrition, School of Medical Sciences, Faculty of Medical and Health Sciences, The University of Auckland, \\ Private Bag 92019, Auckland 1142, New Zealand \\ ${ }^{2}$ School of Allied Health Sciences and Centre for Health Practice Innovation, Griffith University, Parklands Drive, Southport, \\ Gold Coast, QLD 4222, Australia \\ ${ }^{3}$ Department of General Practice and Primary Health Care, Faculty of Medical and Health Sciences, \\ The University of Auckland, New Zealand \\ ${ }^{4}$ School of Human Movement Studies, the University of Queensland, Brisbane, QLD 4072, Australia
}

Correspondence should be addressed to Jennifer Crowley; jcro057@aucklanduni.ac.nz

Received 8 September 2014; Accepted 3 November 2014

Academic Editor: Caryl Nowson

Copyright (C) 2015 Jennifer Crowley et al. This is an open access article distributed under the Creative Commons Attribution License, which permits unrestricted use, distribution, and reproduction in any medium, provided the original work is properly cited.

Throughout the world, medical students and doctors report inadequate nutrition education and subsequently lack of knowledge, attitude, and skills to include nutrition in patient care. This study described New Zealand's students' attitudes to and self-perceived skills in providing nutrition care in practice as well as perceived quantity and quality of nutrition education received in training. 183 medical students from New Zealand's largest medical school (response rate 52\%) completed a 65-item questionnaire, partially validated, using 5-point Likert scales. Students believed incorporating nutrition care into practice is important, yet they were less confident patients improve nutrition behaviours after receiving this care. Students were confident in skills related to nutrition in health and disease but less confident in skills related to general food knowledge. Greater quantity and quality of nutrition education received was associated with greater self-perceived skills in providing nutrition care to patients but not with attitudes towards incorporating nutrition care into practice. This cohort of New Zealand medical students places similarly high importance on nutrition care as students and doctors from other countries. Further investigations beyond graduation are required to inform whether additional nutrition education is warranted for these doctors.

\section{Introduction}

The incidence of chronic disease in New Zealand is growing [1]. The role of nutrition in the prevention and management of chronic disease is well recognised $[2,3]$. It is a priority target of the New Zealand Health Strategy to improve the dietary behaviour of individuals [1]. Primary health care has been identified as an ideal setting to provide nutrition care to patients with chronic disease $[1,4]$. In this setting, nutrition care refers to any practice conducted by a health professional that aims to improve the nutrition behaviour and subsequent health of patients [5].

Approximately thirty percent of New Zealand medical students express a strong interest in becoming general practitioners (GPs) when leaving medical school [6]. General practitioners have the potential to make a significant contribution to the prevention and management of chronic disease in New Zealand by providing nutrition care for three reasons. First, GPs are often the initial contact point for health care of individuals with chronic disease [7]. Second, over three 
TABLE 1: Description of each section of the questionnaire.

\begin{tabular}{|c|c|}
\hline Section & Description of questions \\
\hline $\begin{array}{l}\text { Attitudes towards incorporating } \\
\text { nutrition care into practice }\end{array}$ & $\begin{array}{l}33 \text { questions exploring the perceived importance of nutrition care, implementation of nutrition care, } \\
\text { doctor-patient relationship in nutrition, and efficacy of doctors in providing nutrition care. }\end{array}$ \\
\hline $\begin{array}{l}\text { Self-perceived skills in providing } \\
\text { nutrition care }{ }^{b}\end{array}$ & 30 questions exploring confidence in skills relevant to nutrition care. \\
\hline Nutrition education & $\begin{array}{c}\text { Two questions exploring perceived quantity and quality of nutrition education received during } \\
\text { medical training. }\end{array}$ \\
\hline
\end{tabular}

aAdapted from McGaghie et al. (2001) [22].

${ }^{\mathrm{b}}$ Adapted from Mihalynuk et al. (2003) [23].

quarters (78\%) of the adult New Zealand population consult a GP at least once each year [1]. Third, GPs are one of the most trusted providers of nutrition care [8-11].

There is evidence that GPs can provide effective nutrition care that results in improvements in patients' nutrition behaviour [12-14]. However, the competence of GPs in providing nutrition care has previously been questioned, and it is reported that GPs receive insufficient nutrition education during medical training $[10,15,16]$. As a result, GPs perceive that they are inadequately prepared to provide nutrition care to patients and report low self-efficacy in this area [17-20]. However, it is unclear whether the findings reported in international literature extend to the New Zealand primary care context [21]. In New Zealand's largest medical school, undergraduate training is taught using a systems-based curriculum. Nutrition education does not have a dedicated domain and is taught within the preclinical systems curriculum (years 2 and 3 ) and in clinical years (years 4, 5, and 6). Students receive approximately twenty hours of nutrition teaching, similar to the United States national average of 19.6 hours [16]. The teaching is predominantly didactic, taught by a dietitian in collaboration with other medical educators and includes one three-hour nutrition laboratory.

Competence refers to an individual's ability to perform a task and includes three components: knowledge of a task, skill to perform a task, and attitude that enables task performance [24]. The investigation of self-perceived skills and attitudes in medical students is an accepted indicator of competence when objectives are clearly specified $[23,25]$. As prospective GPs, medical students in the final stages of their university training are an ideal group to investigate skills and attitudes towards incorporating nutrition care into practice. It is presently unclear whether self-perceived skills and attitudes are mediated by the perceived quantity and/or quality of nutrition education received during medical training. Investigating this relationship will assist in understanding if additional nutrition education is required during medical training and will inform strategies to support future GPs to increase competence in nutrition care.

This study described New Zealand medical students' (i) attitudes towards incorporating nutrition care into practice, (ii) self-perceived skills in providing nutrition care, and (iii) perceived quantity and quality of nutrition education received during medical training.

\section{Materials and Methods}

This study utilised a cross-sectional design and was approved by the relevant institutional human research ethics committee (reference number 7785).

Potential participants were students enrolled in two consecutive cohorts from the largest of one of two New Zealand medical schools. The students had finished their coursework and placements and were eligible to graduate ( $n=351)$. In 2012, there were one hundred and sixty two graduate students and, in 2013, one hundred and eighty nine graduate students. There were no differences between the two cohorts for nutrition content and number of hours taught. Data collection occurred each year on a single day when students attended university to complete administrative tasks prior to graduation. To avoid bias, a person not involved with the study administered the process. Information relating to the study was provided to all medical students through the online student information system two months and one month prior to data collection.

A survey was developed from previously used surveys of medical students' attitudes to nutrition care [22] and GP registrars confidence in providing nutrition care [23] and included three sections (Table 1). McGaghie et al's [22] survey has proven reliability and Mihalynuk et al.s [23] survey exhibits construct validity. Where necessary, wording was modified for relevance to the New Zealand context (such as using kilojoules instead of calories). Each item was measured using a 5-point Likert scale, where 1 indicated negative attitude or low confidence and 5 indicated positive attitude or high confidence. The survey was tested with a group of five final year medical students for clarity of understanding, three months prior to final examinations.

Data analysis was conducted using SPSS version 22. Representativeness of the sample for gender and age was investigated using a Chi-squared goodness of fit test and a single sample $t$-test. Descriptive statistics were calculated for each survey item. The relationship between students' perceived quantity and quality of nutrition education was received during medical training, their attitudes towards incorporating nutrition care into practice and self-perceived skills in providing nutrition care were investigated using Pearson's Chi-squared tests. In order to comply with the assumptions underpinning Chi-square tests, categories were collapsed to ensure that $<20 \%$ of cells remained below minimum counts. Statistical significance was set at $P \leq 0.05$. 


\section{Results}

A total of 183 out of 351 eligible students completed the questionnaire, resulting in a response rate of 52\%. Seventeen surveys were excluded because of incomplete data. The majority of participating students $(n=108,59 \%)$ were female, and the average age of the sample was $24.8(\mathrm{SD}=2.5)$ years. There were no significant differences between the participating and nonparticipating students with regards to age (average population age $=25.1$ years; $P=0.277$ ) or gender (population 55\% female; $P=0.211$ ).

Table 2 displays students' attitudes towards incorporating nutrition care into practice. Nearly all students reported that patient motivation, advocating for healthy lifestyle behaviours, and support from other health professionals were important when providing nutrition care. In contrast, students reported variable attitudes about the likelihood of patients changing nutrition behaviour after receiving nutrition care from their doctor.

Table 3 displays students' self-perceived skills in providing nutrition care. Students were confident in skills related to the role of nutrition in health and disease, for example, calculating body mass index and waist-hip ratio, explaining the significance of modest weight loss for patients with type 2 diabetes, and explaining the influence of alcohol consumption on health. Students were less confident in skills associated with the nutrition composition of foods and general food knowledge, for example, assessing total kilojoules and saturated fat per portion of food, explaining how to identify anti-oxidant rich produce, and indicating when to use single vitamins or multivitamins.

The majority of students (60\%) perceived the quantity of nutrition education received during medical training to be good or very good, and even more (83\%) perceived the quality of nutrition education received during medical training to be good or very good. The perceived quantity and quality of nutrition education received during medical training had limited association with students' attitudes towards incorporating nutrition care into practice (Table 2). However, students who reported higher confidence in providing nutrition care were also more likely to perceive the quality and quantity of nutrition education received during medical training to be good or very good (Table 3 ).

\section{Discussion}

This is the first study tov investigate the nutrition-related competence of New Zealand medical students by measuring their attitudes towards incorporating nutrition care into practice and self-perceived skills in providing nutrition care to patients. The results indicated that students felt incorporating nutrition care into practice is important for doctors. However, they were less sure about the capacity of patients to improve their nutrition behaviour after receiving nutrition care by doctors. Students felt more confident discussing the role of nutrition in health and disease than explaining the nutrient composition of foods to patients.
International literature has demonstrated that nutrition care is perceived to be important by medical students, doctors, and medical educators [5, 23, 26, 27]. The results of the present study indicate that similar perceptions exist amongst New Zealand medical students. Despite these positive views, previous studies suggest that students' attitudes towards nutrition care decline after graduation [28-30]. Although attitudes towards nutrition care are positive in students about to graduate, it may still be important to reinforce the significance of nutrition care during the early stages of their career $[21,31]$.

Although students in the present study reported that nutrition care is important, they were less confident that patients would improve their nutrition behaviour after receiving nutrition care from doctors. This suggests that the nutrition-related self-efficacy of this group of students may be low. Given that self-efficacy is a barrier to incorporating nutrition care into practice $[28,32,33]$, it is plausible that the students in the present study, despite thinking nutrition care is important, will not provide this care at every appropriate opportunity. It may also be that students were less confident that patients would improve their nutrition behaviour reflecting the reality of their practical experiences that changing dietary behaviour is very difficult and many patients are resistant to change. It may also be that nutrition care may not be modelled by senior doctors as part of medical practice. Further investigation for reasons why students feel less confident patients will improve nutrition behaviour after receiving nutrition care from doctors is required. This may include developing strategies to improve the nutritionrelated self-efficacy of these students given that nutrition care provided by doctors can positively impact patients' nutrition behaviour [14].

Medical educators have highly variable views on the most important and relevant nutrition-related competencies for students to develop during medical training [5, 34]. Students in the present study were aligned with findings from previous studies, whereby they felt confident in skills related to describing the role of nutrition in health and disease [35]. However, they did not feel confident in skills related to nutrition composition of foods and general food knowledge. Given that these students also perceive that nutrition care should involve the support of other health professionals, such as nurses and dietitians, the specific nutrition-related skills required by doctors may not be universal. This suggests that the ideal role of doctors in providing nutrition care may be to engage with patients regarding their nutrition care needs and ensure access to supporting health professionals when required [34]. Notably, broader health care reforms are focusing on this type of patient-centered approach to care [36].

It has been reported in many international studies that students receive inadequate nutrition education in medical training $[16,37]$. Early reports indicated that over $85 \%$ of medical students were not satisfied with some aspect of their nutrition education [38] and dissatisfaction still exists among the majority of students [16]. In contrast, most students in this New Zealand sample perceived the quality and quantity of nutrition education to be good or very good. One reason 


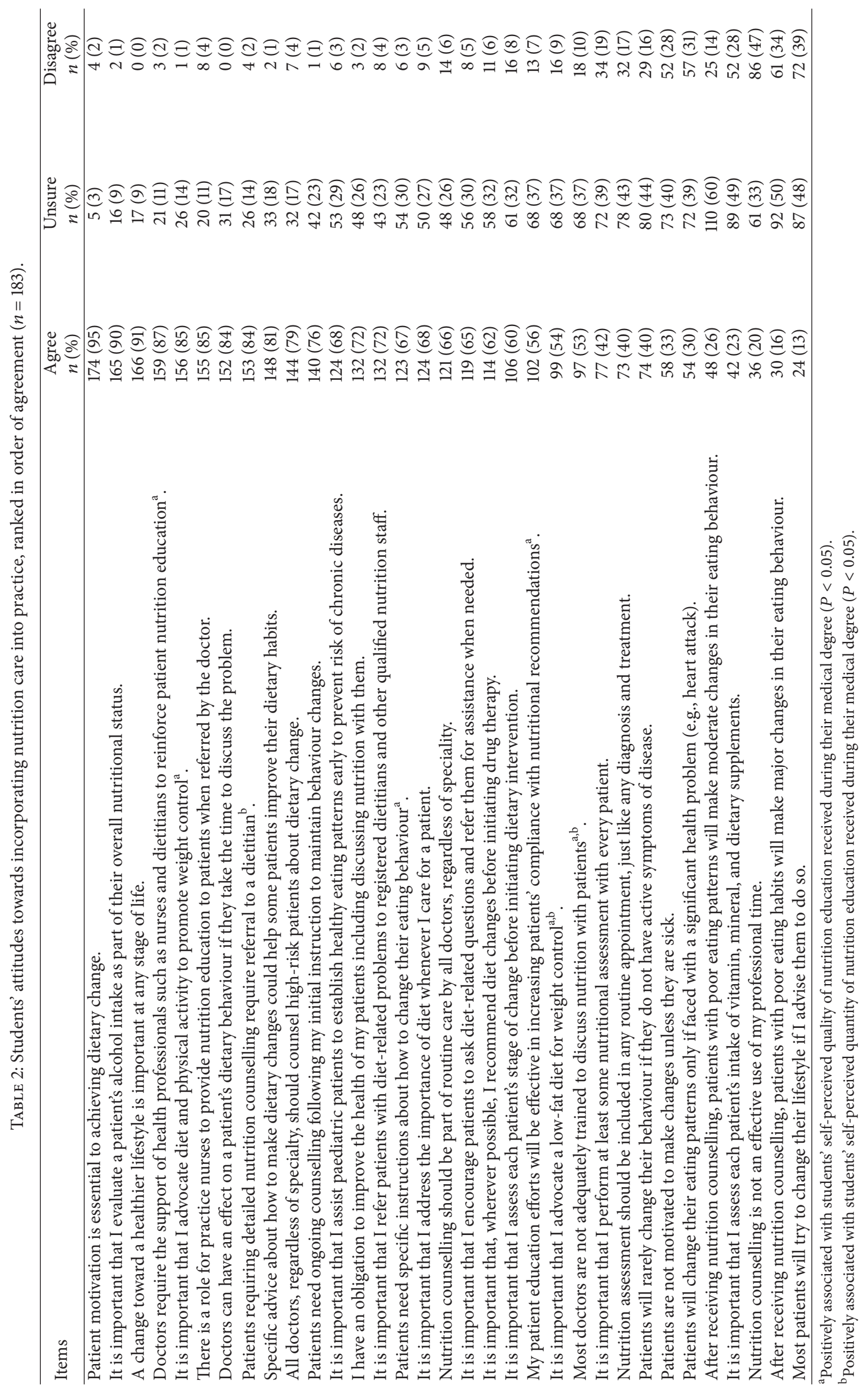




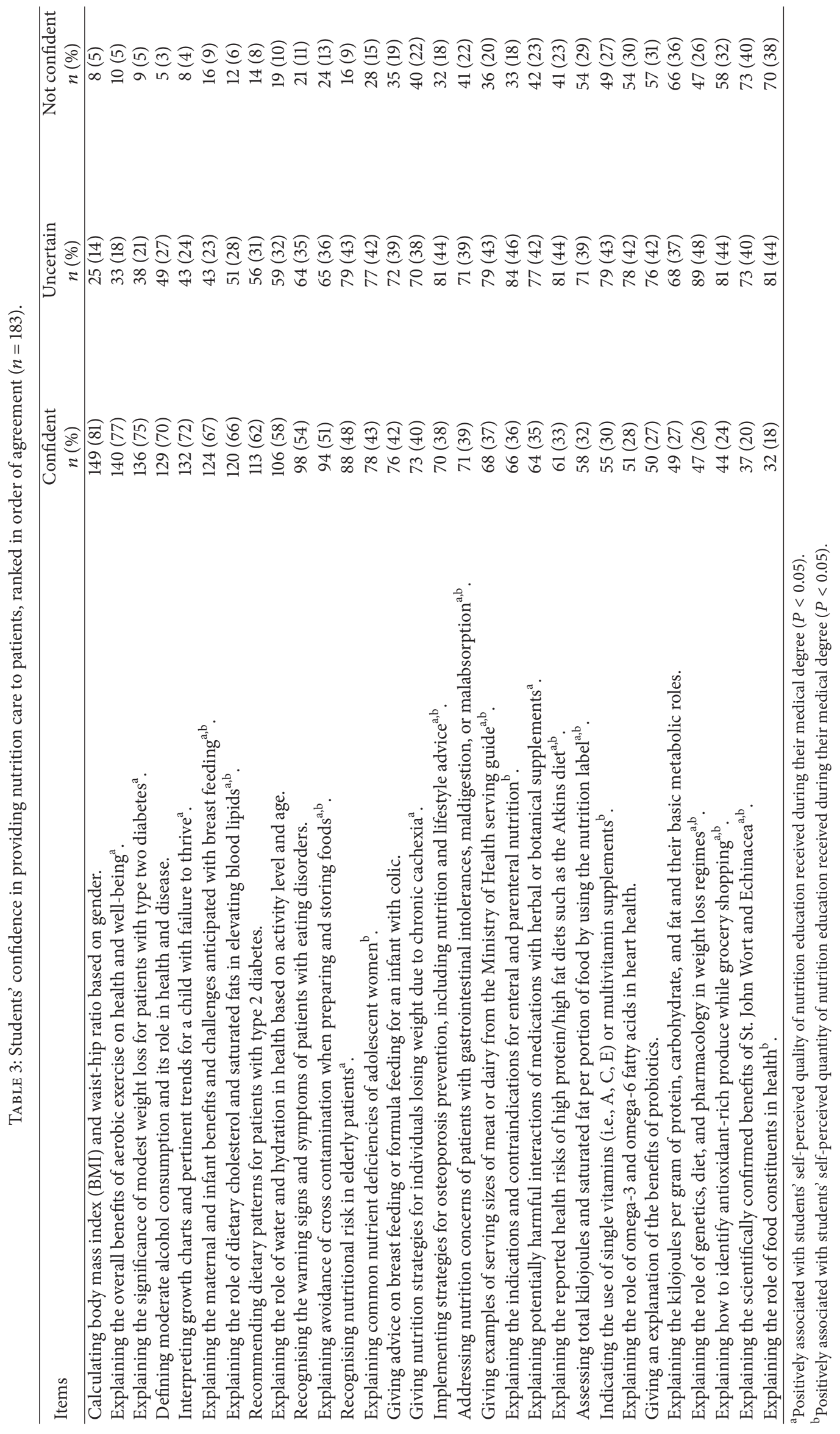


why the results of the present study may have differed from international studies is because students are taught by a nutrition expert (dietitian), which has been recognised as critical to the success of nutrition education programmes and is lacking in many international medical schools [34]. Clearly, further research is required to identify the specific components of nutrition education required to meet the learning needs of New Zealand medical students.

The present study indicated that students' self-perceived skills in providing nutrition care were positively associated with the nutrition education received during medical training. However, there was a limited relationship between perceptions of quantity and quality of nutrition education and students' attitudes towards nutrition care. This suggests that the quantity and quality of medical education are likely to influence the nutrition-related skill development of students. This is consistent with findings reported in international literature $[16,39]$. However, the somewhat rudimentary measure of nutrition education quantity and quality used in this study prevents definitive conclusions in the New Zealand context.

The present study has noteworthy strengths and limitations. Previous studies have utilised various methods to investigate the attitudes and self-perceived skills of medical students in providing nutrition care. The use of two previously validated tools to guide the development of the questionnaire in the current study enhances the confidence in findings, which can be used to inform future studies in New Zealand. However, with a response rate of $52 \%$ of the potential participant pool, it is possible that students interested in nutrition were more likely to complete the questionnaire and this may have overestimated the attitudes and self-perceived skills reported in this study. Furthermore, this study relates to only one of the two medical schools in New Zealand, and generalisability of the results should be cautioned. There is no consensus method for assessing the quantity and quality of medical nutrition education and this remains a challenge for the future. Finally, further research is required to determine whether attitudes and self-perceived skills in nutrition care influence students' future provision of nutrition care in practice and ultimately the health of their patients.

\section{Conclusion}

In conclusion, New Zealand medical students feel that incorporating nutrition care into practice is important for doctors. However, they believed the capacity of patients to improve their nutrition behaviour after receiving nutrition care by doctors is somewhat limited. Students perceived the quantity and quality of nutrition education received during medical training to be good. Further investigation of students' attitudes and self-perceived skills in providing nutrition care after graduation will inform whether additional nutrition education is warranted for these doctors. Considering that New Zealand GPs are well placed to provide nutrition care to patients with chronic disease, they may require support dealing with the barriers to providing this care to patients.

\section{Conflict of Interests}

The authors declare that there is no conflict of interests regarding the publication of this paper.

\section{References}

[1] Ministry of Health, The Health of New Zealand Adults 2011/12, Ministry of Health, Wellington, New Zealand, 2012.

[2] World Health Organization, Diet, Nutrition and the Prevention of Chronic Diseases, WHO, Geneva, Switzerland, 2003.

[3] United States Department of Health and Human Services and Office of Disease Prevention and Health Promotion, "Healthy People 2020," 2013, http://www.healthypeople.gov/ 2020/default.aspx.

[4] M. F. Harris, The Role of Primary Health Care in Preventing the Onset of Chronic Disease, with a Particular Focus on the Lifestyle Risk Factors of Obesity, Tobacco and Alcohol, Sydney Centre for Primary Health Care and Equity, Sydney, Australia, 2008.

[5] L. E. Ball, R. M. Hughes, and M. D. Leveritt, "Nutrition in general practice: role and workforce preparation expectations of medical educators," Australian Journal of Primary Health, vol. 16, no. 4, pp. 304-310, 2010.

[6] P. Poole, D. Bourke, and B. Shulruf, "Increasing medical student interest in general practice in New Zealand: where to from here?" New Zealand Medical Journal, vol. 123, no. 1315, pp. 12-19, 2010.

[7] Ministry of Health, "Visiting a doctor," 2014, http://www.health. govt.nz/your-health/services-and-support/health-care-services /visiting-doctor.

[8] L. Ball, B. Desbrow, and M. Leveritt, "An exploration of individuals' preferences for nutrition care from Australian primary care health professionals," Australian Journal of Primary Health, vol. 20, no. 1, pp. 113-120, 2014.

[9] A. A. Jackson, "Educational group lecture. Human nutrition in medical practice: the training of doctors," Proceedings of the Nutrition Society, vol. 60, no. 2, pp. 257-263, 2001.

[10] K. Kolasa, "Developments and challenges in family practice nutrition education for residents and practicing physicians: an overview of the North American experience," European Journal of Clinical Nutrition, vol. 53, supplement 2, pp. S89-S96, 1999.

[11] G. J. Hiddink, J. G. A. J. Hautvast, C. M. J. van Woerkum, C. J. Fieren, and M. A. van 't Hof, "Consumers' expectations about nutrition guidance: the importance of primary care physicians," American Journal of Clinical Nutrition, vol. 65, no. 6, pp. 1974S1979S, 1997.

[12] T. C. Keysering, A. S. Ammermann, C. E. Davis et al., "A randomised controlled trial of physician directed program for low income patientss with high blood cholesterol: The Southeast Cholesterol Project," Archives of Family Medicine, vol. 6, no. 2, pp. 134-145, 1997.

[13] I. S. Ockene, J. R. Herbert, J. K. Okene et al., "Effect of physician-delivered nutrition counseling training and an office support program on saturated fat intake, weight and serum lipid measurements in hyperlipidemia Worcester Area Trail for Counseling in Hyperlipidemia (WATCH)," Archives of Internal Medicine, vol. 157, pp. 725-731, 1999.

[14] L. Ball, C. Johnson, B. Desbrow, and M. Leveritt, "General practitioners can offer effective nutrition care to patients with lifestylerelated chronic disease," Journal of Primary Health Care, vol. 5, no. 1, pp. 59-69, 2013. 
[15] F. Leslie and S. Thomas, "Competent to care. Are all doctors competent in nutrition?" Proceedings of the Nutrition Society, vol. 68, no. 3, pp. 296-299, 2009.

[16] K. M. Adams, M. Kohlmeier, and S. H. Zeisel, "Nutrition education in U.S. medical schools: latest update of a national survey," Academic Medicine, vol. 85, no. 9, pp. 1537-1542, 2010.

[17] K. Glanz, "Review of nutritional attitudes and counseling practices of primary care physicians," American Journal of Clinical Nutrition, vol. 65, no. 6, pp. 2016S-2019S, 1997.

[18] J. A. Cimino, "Why can't we educate doctors to practice preventive medicine?” Preventive Medicine, vol. 25, no. 1, pp. 6365, 1996.

[19] K. S. Soltesz, J. H. Price, L. W. Johnson, and S. K. Tellijohann, "Family physicians' views of the preventive services task force recommendations regarding nutritional counseling," Archives of Family Medicine, vol. 4, no. 7, pp. 589-593, 1995.

[20] R. F. Kushner, "Barriers to providing nutrition counseling by physicians: a survey of primary care practitioners," Preventive Medicine, vol. 24, no. 6, pp. 546-552, 1995.

[21] J. Crowley, L. Ball, C. Wall, and M. Leveritt, "Nutrition beyond drugs and devices: a review of the approaches to enhance the capacity of nutrition care provision by general practitioners," Australian Journal of Primary Health, vol. 18, no. 2, pp. 90-95, 2012.

[22] W. C. McGaghie, L. van Horn, M. Fitzgibbon et al., "Development of a measure of attitude toward nutrition in patient care," The American Journal of Preventive Medicine, vol. 20, no. 1, pp. 15-20, 2001.

[23] T. V. Mihalynuk, C. S. Scott, and J. B. Coombs, "Self-reported nutrition proficiency is positively correlated with the perceived quality of nutrition training of family physicians in Washington State," The American Journal of Clinical Nutrition, vol. 77, no. 5, pp. 1330-1336, 2003.

[24] S. Verma, M. Paterson, and J. Medves, "Core competencies for health care professionals: what medicine, nursing, occupational therapy, and physiotherapy share," Journal of Allied Health, vol. 35, no. 2, pp. 109-115, 2006.

[25] D. A. Davis, P. E. Mazmanian, M. Fordis, R. Van Harrison, K. E. Thorpe, and L. Perrier, "Accuracy of physician self-assessment compared with observed measures of competence: a systematic review," The Journal of the American Medical Association, vol. 296, no. 9, pp. 1094-1102, 2006.

[26] M. L. Vetter, S. J. Herring, M. Sood, N. R. Shah, and A. L. Kalet, "What do resident physicians know about nutrition? An evaluation of attitudes, self-perceived proficiency and knowledge," Journal of the American College of Nutrition, vol. 27, no. 2, pp. 287-298, 2008.

[27] A. Helman, "Nutrition and general practice: an australian perspective," The American Journal of Clinical Nutrition, vol. 65, no. 6, pp. 1939S-1942S, 1997.

[28] E. H. Spencer, E. Frank, L. K. Elon, V. S. Hertzberg, M. K. Serdula, and D. A. Galuska, "Predictors of nutrition counseling behaviors and attitudes in US medical students," The American Journal of Clinical Nutrition, vol. 84, no. 3, pp. 655-662, 2006.

[29] B. W. Jack, A. B. Lasswell, W. McQuade, and L. Culpepper, "A follow-up survey of family physicians' interest in and knowledge of nutrition," Academic Medicine, vol. 65, no. 11, pp. 710-712, 1990.

[30] S. G. Mlodinow and E. Barrett-Connor, "Physicians' and medical students' knowledge of nutrition," Academic Medicine, vol. 64, no. 2, pp. 105-106, 1989.
[31] R. F. Kahn, "Continuing Medical Education in nutrition," The American Journal of Clinical Nutrition, vol. 83, no. 4, supplement, pp. 981S-984S, 2006.

[32] J. A. S. Carson, M. B. Gillham, L. M. Kirk, S. T. Reddy, and J. B. Battles, "Enhancing self-efficacy and patient care with cardiovascular nutrition eduction," American Journal of Preventive Medicine, vol. 23, no. 4, pp. 296-302, 2002.

[33] S. Katz, A. Feigenbaum, S. Pasternak, and S. Vinker, "An interactive course to enhance self-efficacy of family practitioners to treat obesity," BMC Medical Education, vol. 5, article 4, 2005.

[34] R. F. Kushner, L. Van Horn, C. L. Rock et al., "Nutrition education in medical school: a time of opportunity," The American Journal of Clinical Nutrition, vol. 99, no. 5, pp. 1167S-1173S, 2014.

[35] L. M. Gramlich, D. L. Olstad, R. Nasser et al., "Medical students' perceptions of nutrition education in Canadian universities," Applied Physiology, Nutrition and Metabolism, vol. 35, no. 3, pp. 336-343, 2010

[36] World Health Organisation, London Declaration: Patients for Patient Safety, World Health Organisation, Geneva, Switzerland, 2006.

[37] W. A. Walker, "Advances in nutritional education for medical students," The American Journal of Clinical Nutrition, vol. 72, supplement, pp. 865S-867S, 2000.

[38] R. L. Weinsier, J. R. Boker, E. B. Feldman, M. S. Read, and C. M. Brooks, "Nutrition knowledge of senior medical students: a collaborative study of southeastern medical schools," American Journal of Clinical Nutrition, vol. 43, no. 6, pp. 959-968, 1986.

[39] K. M. Kolasa, "Images' of nutrition in medical education and primary care," The American Journal of Clinical Nutrition, vol. 73, no. 6, pp. 1006-1009, 2001. 

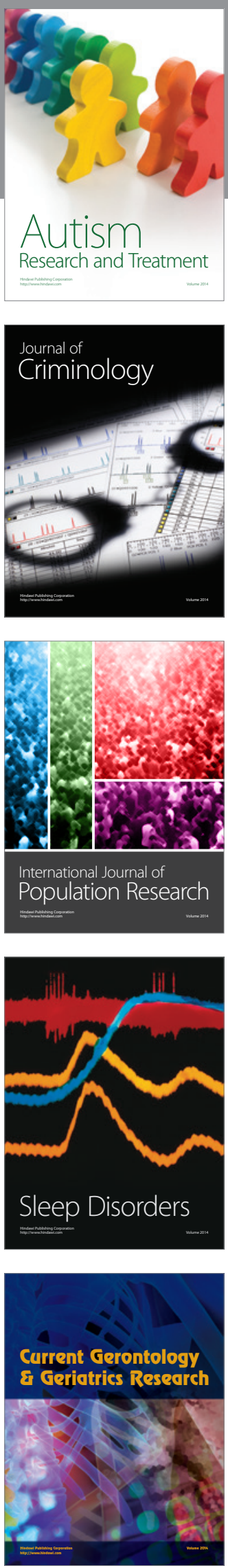
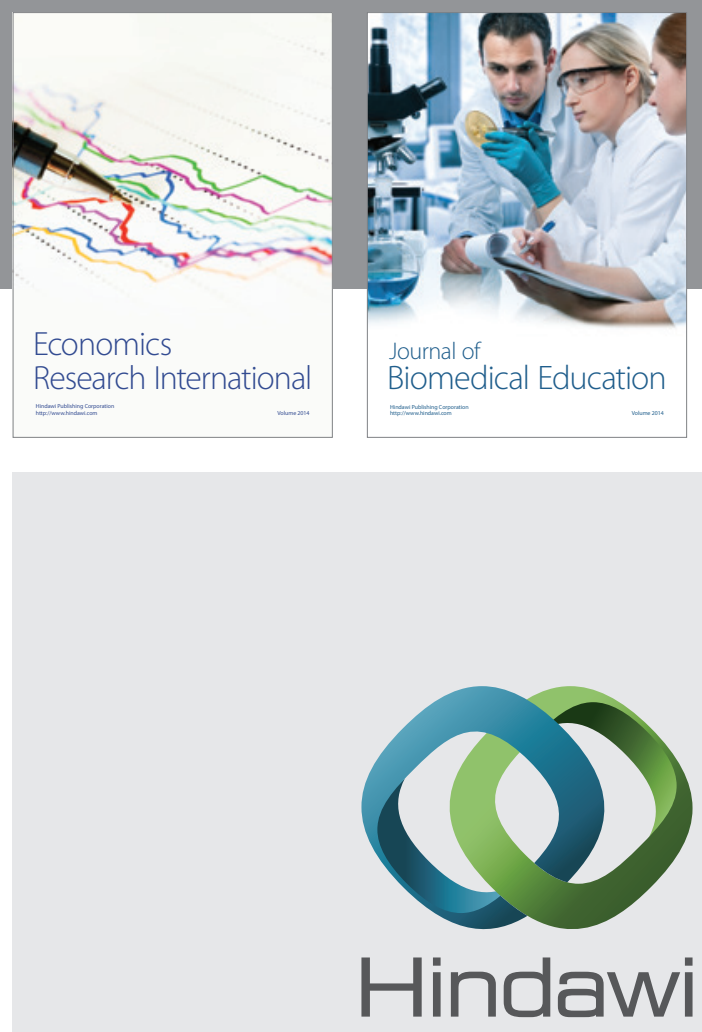

Submit your manuscripts at

http://www.hindawi.com
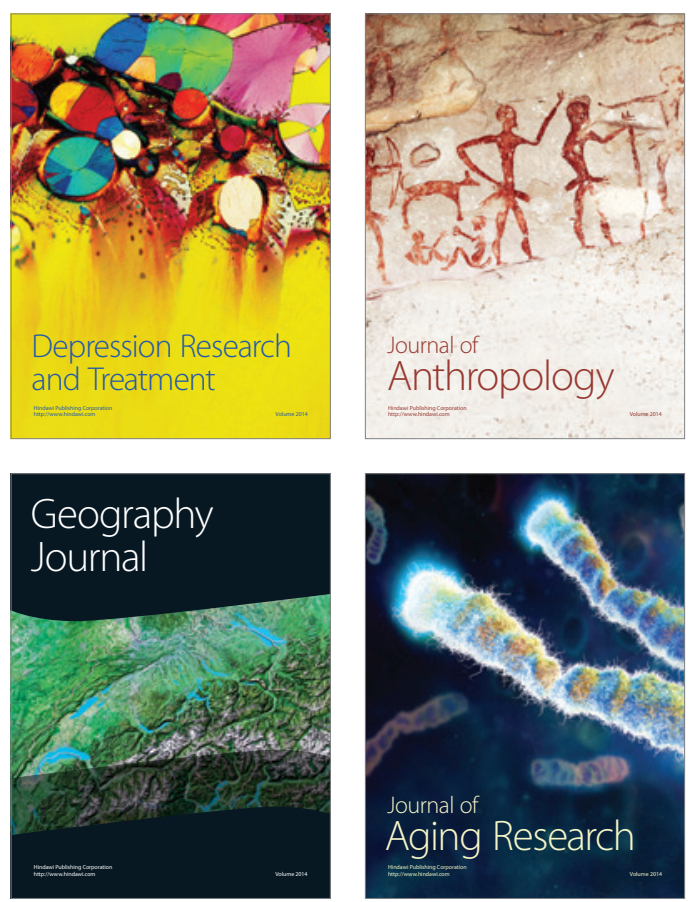
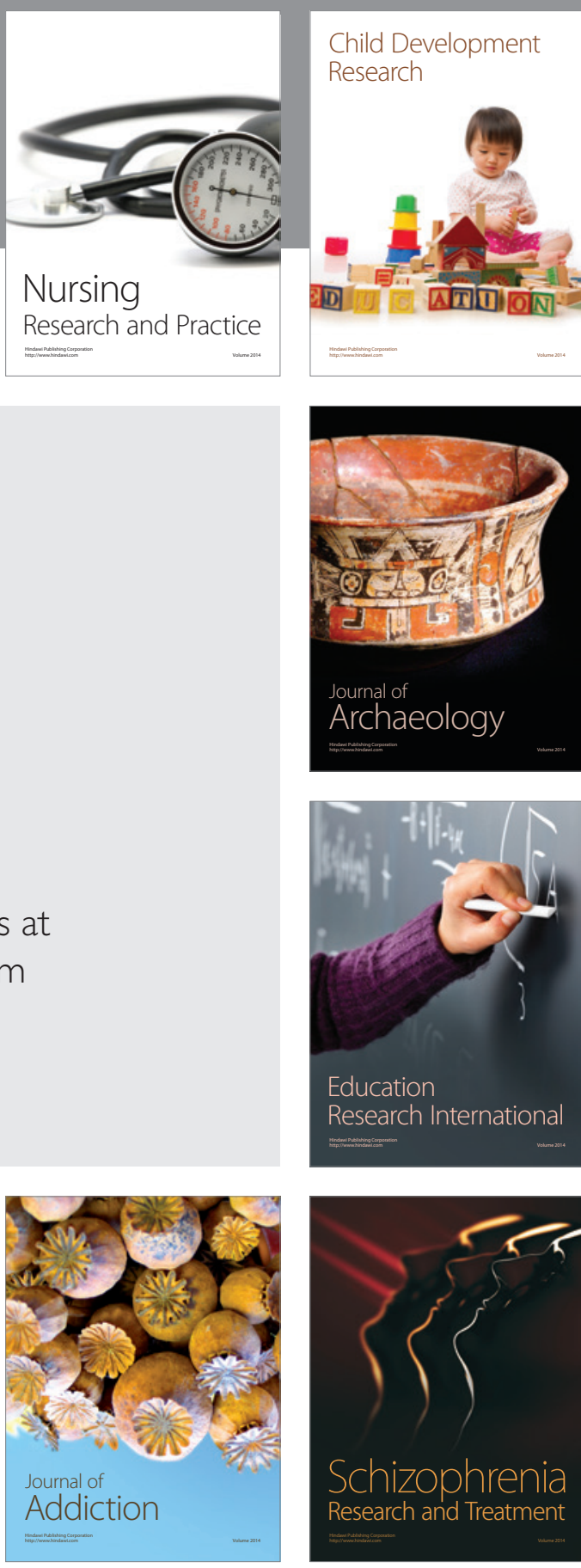

(D)
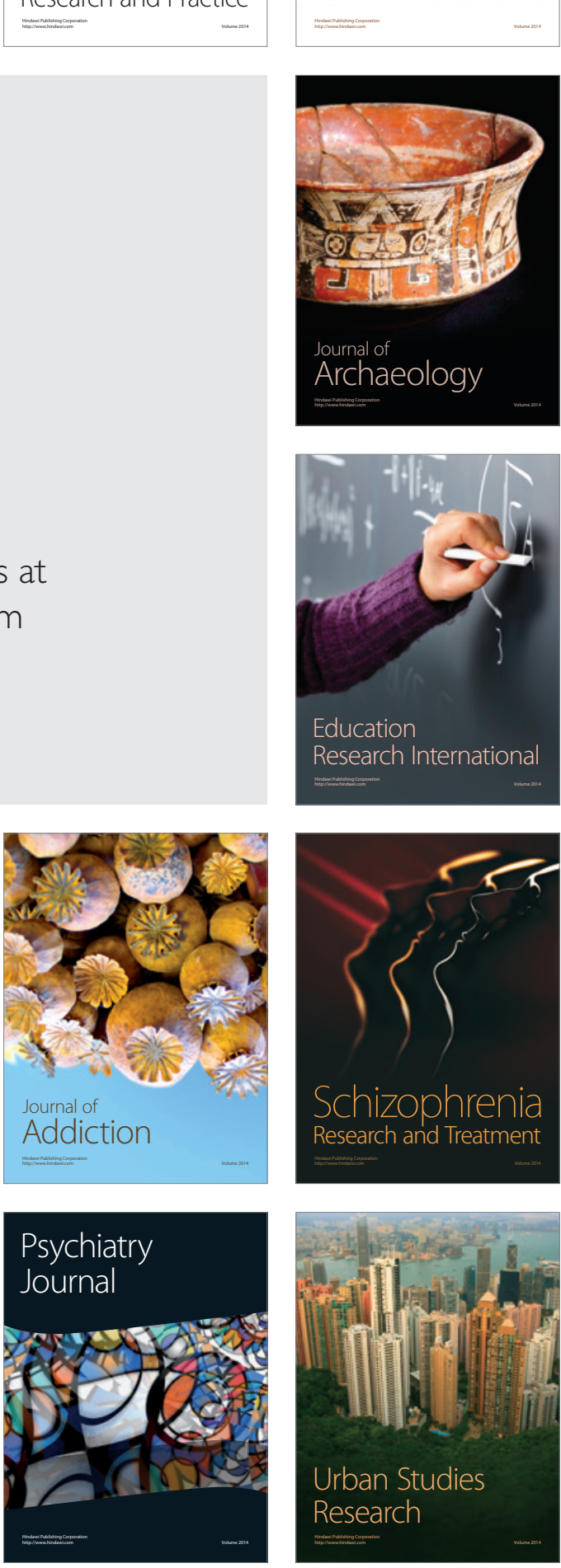